\title{
GLONASS Receivers Calibration
}

\author{
Dmitry S. Pecheritsa* \\ Russian Metrological Institute \\ of Technical Physics and Radio Engineering \\ Mendeleevo, Moscow region, 141570, Russia
}

Received 25.06.2018, received in revised form 29.06.2018, accepted 13.07.2018

The research presents the method and the results of calibration of GLONASS receivers in the pseudorange measurement error (bias). The method is based on the application of the instruments providing traceability to national primary standards of values. The influence of pseudorange biases to positioning error are described in the work.

Keywords: GNSS, GLONASS, receiver, GNSS simulator, navigation signal.

Citation: Pecheritsa D.S. GLONASS Receivers Calibration, J. Sib. Fed. Univ. Eng. technol., 2019, 12(1), 126-131 DOI: 10.17516/1999-494X-0078.

\section{Калибровка навигационной аппаратуры потребителей ГЛОНАСС}

Д.С. Печерица

Всероссийский научно-исследовательский институт физико-технических и радиотехнических измерений Россия, 141570, Московская область, Менделеево

Представлен метод и результаты калибровки НАП ГЛОНАСС в части систематической инструментальной погрешности измерения псевдодальности (задержки). Метод основан на применении средств, обеспечивающих прослеживаемость измеряемых величин к первичным государственным эталонам единиц величин. Показаны результаты учета результатов калибровки на погрешность определения координат.

Ключевые слова: ГНСС, ГЛОНАСС, НАП, имитатор сигналов, навигационный сигнал.

(C) Siberian Federal University. All rights reserved

This work is licensed under a Creative Commons Attribution-NonCommercial 4.0 International License (CC BY-NC 4.0).

* Corresponding author E-mail address: Pecheritsa_ds@vniiftri.ru 


\section{Introduction}

The main purpose of GLONASS navigation equipment (receiver) is to receive and process navigation satellite's (NS) signals in order to define consumer's spatiotemporal data, his velocity vector, attitude reference, etc.

The most common method of solving satellite navigation problem is a pseudorange method. It is based on pseudorange measurement up to NS with the given position and subsequent calculation of its spatiotemporal coordinates. Pseudorange is a range measured with the use of non-inquiry method, i.e. the sum of propagation time and difference of a signal source and a receiver timescales.

The total positional error using pseudorange method is defined by the:

$$
\triangle P O S=\triangle R \cdot P D O P,
$$

$\Delta R$ is the pseudorange measurement error, PDOP (Position Dilution of Precision) is the attitude geometric factor.

Pseudorange measurement error in its turn includes several essential components and might be described like the following [2]:

$$
\Delta R=\Delta_{e p h}+\Delta_{a t m}+\Delta_{r e l}+\Delta_{M}+\Delta_{R E C}+\varepsilon_{R},
$$

$\Delta_{e p h}$ is the contribution to pseudorange measurement error due to ephemeris error, i.e. signal-in-space range error (SISRE), $\Delta_{a t m}$ is the contribution due to navigation signal delay in the atmosphere, $\Delta_{\text {rel }}$ are the contribution due to relativistic and gravitational effects (RGE), $\Delta_{M}$ is the supply due to NS multiple propagation, $\Delta_{R E C}$ is the contribution due to instrumental pseudorange measurement error, $\varepsilon_{R}$ are the other error components.

Table 1 contains all the above described components. The residual values of each errors are given in accordance with [3].

One can see from Table 1 that considering GLONASS system development prospects receiver's instrumental error makes the most significant contribution to the total pseudorange measurement error.

\section{Problem definition}

In order to reach potential precision of location (time) definition that a consumer is able to get by receiving GLONASS signals one must provide crucially small value of instrumental receiver's pseudorange measurement error comparing with the SISRE (minimum 3 times smaller). Thus, the

Table 1. Components of pseudorange measurement error of GLONASS receivers

\begin{tabular}{|c|c|l|}
\hline Source of error & Residual error & \multicolumn{1}{c|}{ Comment } \\
\hline SISRE & 0.7 & by 2018 \\
\hline Atmosphere & 0.4 & $\begin{array}{l}\text { Dual-frequency measurements, application of models } \\
{[1],[2],[3]}\end{array}$ \\
\hline RGE & 0.1 & Application of models [3] \\
\hline Multiple propagation & 0.5 & Antenna structure, processing algorithm [1], [2], [3] \\
\hline Instrumental error & $>2$ & \\
\hline
\end{tabular}


requirements for instrumental receiver's pseudorange measurement are possible to describe with the value of $0.2 \mathrm{~m}$ (requirements for the system of the year 2018).

The main reason of instrumental receiver's measurement error is a navigation signal delay in receiver's path. Receiver's radio-frequency path includes frequency-dependent elements the navigation signal propagation delay of which depends on the signal spectral characteristics. GLONASS system applies signals frequency division in several frequency band that is why the delay of all received signals will be different. This fact explains the presence of instrumental receiver's pseudorange measurement error. The values of this error might reach some meters values for different letters within the one frequency range and exceed 10 meters for signals from different frequency ranges. Due to its nature, instrumental receiver's measurement error has a systematic character that means it might be defined according to calibration results and used in measurements. Calibration here and elsewhere means a procedure of systematic component of instrumental pseudorange measurement error (bias) definition.

One must provide a residual receiver's error not bigger than $0.2 \mathrm{~m}$. Consequently combined standard receiver calibration uncertainty must not exceed $0.1 \mathrm{~m}$ (with a sweep ratio equal to 2 ).

\section{Theory}

As it was said above the measured pseudorange has a systematic error the value of which depends on operational frequency of navigation signal and is caused by group delay (GD) dependence in receiver's radiofrequency path. Radiofrequency path might be divided in two basic components: antenna feeder device (AFD) with a cable and receiving-measuring device path. It is evident that each component contributes to the total systematic pseudorange measurement error. Thus receiver calibration in the part of systematic component of instrumental pseudorange measurement error (bias) means the calibration of separate components.

AFD calibration comes down to GD measurement in antenna path as well for different operational frequencies values, different elevation and azimuth. The measurements are effected with the help of specially developed equipment set for AFD parameters measurement. The set includes a standard unit of group delay in receiver's antenna within the frequency range from $1.1 \mathrm{GHz}$ up to $1.7 \mathrm{GHz}$, that is traced to the primary special standard length unit National Standard 199-2018 and to primary standard of wave resistance in coaxial waveguide NS 75-2011.

The calibration method of receiving-measuring device is based on seminatural modeling of navigation signal with the use of GNSS signals simulators which serve as standard navigational signal source. The measuring diagram is presented at Fig. 1.

As one can see from the diagram the simulator and the receiver uses the same reference frequency and their timescales are synchronized. That means that the simulator timescale (TS) simultaneously is both a TS of a system and a TS of a consumer. This fact allows eliminating pseudorange component caused by the difference of these timescales.

One set up formation of navigation circumstances on the simulator with the following parameters:

- traffic model - solid point;

- shaping signals - all that can be received by receiver's-measuring device;

- atmospheric effects shaping - off;

- formation of ephemeris-temporal supply - off. 


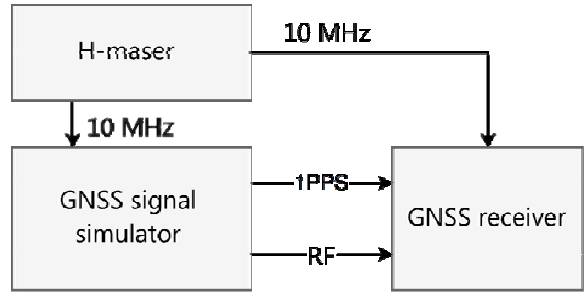

Fig. 1. Measuring diagram

Considering the above mentioned circumstances the model of shaping pseudorange for every time moment is represented in the following way:

$$
R_{I M, i}(j)=\rho_{i}(j)+b_{I M, i}+\varepsilon_{I M},
$$

where: $i$ is the stands for the combination of a certain NS and signal types (for instance, standard precision signal within the frequency range L1 NS №1 of GLONASS system), $j$ is the epoch number on which the measurement has been received, $R_{I M, i}(j)$ is the shaping pseudorange, $\rho_{i}(j)$ is the shaping geometric range, $b_{I M, i}$ is the systematic component of instrumental pseudorange measurement error by GNSS signals simulator expressed in meters, $\varepsilon_{I M}$ are the random components of pseudorange measurement error, normally distributed random process.

Pseudorange measured with the receiving-measuring device in its turn is described like this:

$$
R_{\text {rec }, i}(j)=\rho_{i}(j)+b_{I M, i}+\varepsilon_{\text {И }}+b_{r e c},
$$

where $R_{\text {rec }, i}(j)$ is the pseudorange measured with the receiving-measuring device, $b_{\text {rec }, i}$ is the systematic component of instrumental pseudorange measurement error measured with the receiving-measuring device expressed in meters, $\varepsilon_{r e c}$ is the random component of pseudorange measurement error, normally distributed random process.

These measurements are effected within the period of not less than 24 hours in order to provide measurements of all NS. The measurements must be performed within 8 days in order to estimate stability $b_{\text {rec, } i}$ for the reason that during this period GNSS GLONASS satellite constellation will be entirely repeated [1].

The difference between pseudorange of the receiving device and standard data from the simulator in accordance with equations (1), (2) are described in the following way:

$$
R_{r e c, i}(j)-R_{I M, i}(j)=-b_{I M, i}-b_{r e c, i}-\varepsilon,
$$

where $\varepsilon$ is the total random simulator pseudorange error and receiving-measuring device, normally distributed random process.

Measurement noise is eliminated with the help of statistic processing [4]. Therefore the value of $b_{\text {rec }, i}$ can be find according to the formula:

$$
b_{r e c, i}=-b_{I M, i}-\sum_{j=1}^{N}\left(R_{r e c, i}(j)-R_{I M, i}(j)\right) .
$$


Table 2. Receiver calibration uncertainty budget

\begin{tabular}{|l|c|l|}
\hline \multicolumn{1}{|c|}{ Source of uncertainty } & Absolute value, $\mathrm{m}$ & \multicolumn{1}{c|}{ Comments } \\
\hline AFD calibration uncertainty & 0.045 & $\begin{array}{l}\text { Standard measurements uncertainty } \\
\text { of equipment set for AFD parameters } \\
\text { measuring. Symbol } u_{\mathrm{B}}(A)\end{array}$ \\
\hline $\begin{array}{l}\text { Systematic pseudorange formation } \\
\text { uncertainty by signals simulator }\end{array}$ & 0.03 & $\begin{array}{l}\text { GNSS signals simulator uncertainty Symbol } \\
u_{\mathrm{B}}(I M)\end{array}$ \\
\hline Other errors & 0.02 & Standard uncertainty of A-type. Symbol $u_{\mathrm{A}}$ \\
\hline In total & $<0,06$ & \\
\hline
\end{tabular}

As indicated earlier, systematic instrumental CNE error is caused by the total navigation signal propagation delay in the path of the antenna-feeder device and the receiving-measuring device. Thus systematic instrumental CNE error is defined with the following equation:

$$
b_{i}=b_{\mathrm{A}, i} \cdot c-b_{I M, i}-\sum_{j=1}^{N}\left(R_{r e c, i}(j)-R_{I M, i}(j)\right),
$$

Where: $c$ is the light speed, $R_{A, i}$ is the i-navigation signal propagation delay in AFD path multiplied by light, $b_{I M, i}$ is the systematic instrumental error of pseudorange formation by GNSS signals simulator [5].

Table 2 contains the calculated budget of calibration uncertainty in compliance with Formula (3) [6].

The final calibration uncertainty is calculated using the following formula (4) [6].

$$
u_{\text {rec }}=\sqrt{u_{B}^{2}(V N A)+u_{B}^{2}(A)+u_{B}^{2}(I M)+u_{A}^{2}} .
$$

The final GLONASS receiver calibration uncertainty in the pseudorange bias does not exceed $0.06 \mathrm{~m}$.

\section{Experiments results}

The influence of calibration amendments to systematic component of instrumental receiver's pseudorange measurement error on the error of navigation problem solution is shown in Fig. 2, 3 . The figures describe the errors of coordinates definition in the plane in the statistic mode on geodesic site with given coordinates. The solution of satellite navigation problem was obtained using the least square method in dual-frequency mode within the period of 24 hours with $30 \mathrm{sec}$ interval according GLONASS signals with open access applying ephemeris-temporal information. Fig. 2 explains the result of navigation task solution without calibration amendments, Fig. 3 - with them. The center is a true receiver's position.

Standard error of estimate of coordinates definition error in the plane decreased from $3.6 \mathrm{~m}$ to $2.2 \mathrm{~m}$, i.e. by more than $30 \%$

\section{Conclusion}

The article represents the developed method of calibration GLONASS receivers in the pseudorange bias with traceability up to primary standard values of Russian Federation. Calculation method uncertainty does not exceed $0.06 \mathrm{~m}$ in case of direct calibration. Consideration of calibration 


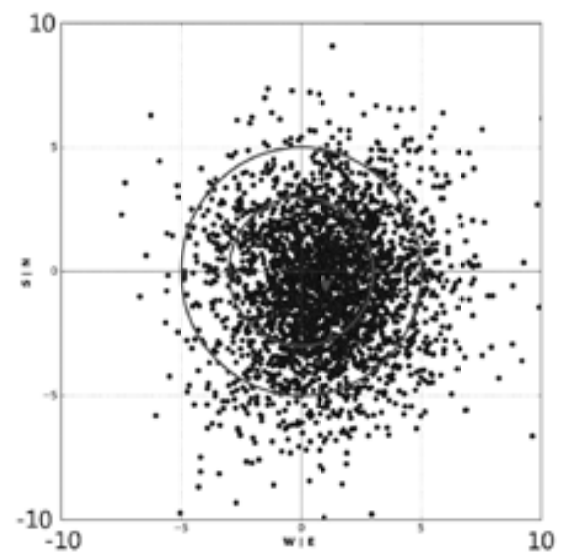

Fig. 2. Coordinates definition error in the plane without calibration amendments in meters

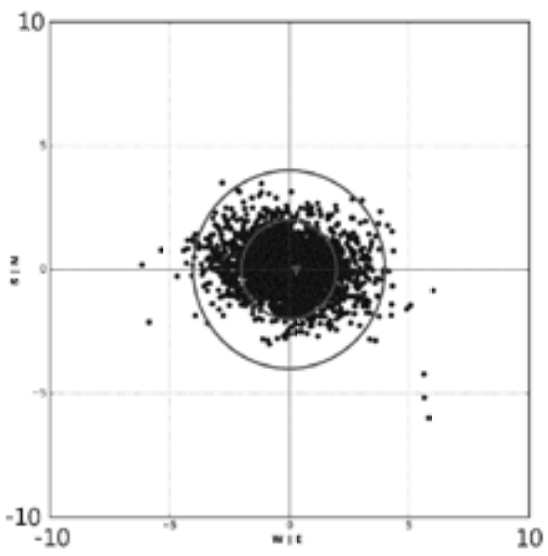

Fig. 3. Coordinates definition error in the plane with calibration amendments in meters

amendments to GLONASS receiver's pseudorange measurement provides the increasing precision of location definition by more than $30 \%$.

\section{References}

[1] Перов А.И., Харисов В.Н. ГЛОНАСС Принциипы построения и функичионирования, М.: Радиотехника, 2010. [Perov A.I. and Kharisov V.N. GLONASS. Buiding-up and functioning principals, Moscow, Radiotekhnica, 2010 (in Russian)]

[2] Hofmann-Wellenhof B., Lichtenegger H. and Wasle E., GNSS - Global navigation satellite systems. GPS, GLONASS, GALILEO and more, Wien, SpringerWienNewYork, 2008.

[3] Janz Subirana J.M., Zornoza M.H.-P., GNSS DATA PROCESSING. Volume I, Fundamentals and Algorithm, Netherlands, ESA Communications, 2013.

[4] ГОСТ Р 8.736-2011 “Государственная система обеспечения единства измерений (ГСИ). Измерения прямые многократные. Методы обработки результатов измерений. Основные положения". [GOST Р 8.736-2011 "State system for ensuring uniform measurement (GSI). Multiple direct measurements. Methods of measurement results processing. Main principals" (in Russian)]

[5] Печерица Д.С., Федотов В.Н. Калибровка имитаторов сигналов ГНСС. Системный анализ, управление и навигация: Тезисы докладов, М., 2016. [Pecheritsa D.S. and Fedotov V.N., Calibration of GNSS signals simulator, System analysis, management and navigation, Lectures abstracts, Moscow, 2016 (In Russian)]

[6] ГОСТ 54500.3-2011-3 «НЕОПРЕДЕЛЕННОСТЬ ИЗМЕРЕНИЯ. Часть 3. Руководство по выражению неопределенности измерения», 2011 [GOST 54500.3-2011-3 “MEASUREMENT UNCERTAINTY. Part 3. Guide to the expression of uncertainty in measuring”, 2011. (In Russian)] 